University for Business and Technology in Kosovo

UBT Knowledge Center

UBT International Conference

2013 UBT International Conference

Nov 2nd, 3:45 PM - 4:00 PM

\title{
Development Of Cost Model For Construction Projects In Albania
}

Valdete Ballhysa

Specialist, General Directorate of Water Supply and Sewerage

Follow this and additional works at: https://knowledgecenter.ubt-uni.net/conference

Part of the Architecture Commons

\section{Recommended Citation}

Ballhysa, Valdete, "Development Of Cost Model For Construction Projects In Albania" (2013). UBT

International Conference. 16.

https://knowledgecenter.ubt-uni.net/conference/2013/all-events/16

This Event is brought to you for free and open access by the Publication and Journals at UBT Knowledge Center. It has been accepted for inclusion in UBT International Conference by an authorized administrator of UBT Knowledge Center. For more information, please contact knowledge.center@ubt-uni.net. 


\title{
Development Of Cost Model For Construction Projects In Albania
}

\author{
Valdete Ballhysa ${ }^{1}$ \\ ${ }^{1}$ Specialist,General directorate of Water Supply and Sewerage, \\ Tirane, Albania
}

\begin{abstract}
Project cost is one of the most important criteria of success of project and is of high concern to those who are involved in the construction industry. As the construction industry is encouraged to adopt innovation in its trade, project cost came to the industry players to review the prevalent method of cost estimation for cost planning and control of projects. Drawing from that, and appreciating the need to reform the construction industry's practices, it was conceived that reviewing the existent construction cost modeling used in the preparation of cost planning and control for projects would be the most expedient and vital. Studies show that rarely projects are complete within stipulated budget. The objective of this paper is, to review the current status of design cost modeling in terms of the techniques used, their accuracy and levels of usage. Types of construction cost modeling are identified through literature rev iew and interviews. This paper presents the results of a questionnaire survey conducted among contractors, designer and project managers. Data was analyzed with PASW statistical program, version 18.This paper concluded that the traditional type of cost estimation models continue to be in widespread use irrespective of organizational type and size.
\end{abstract}

Keywor ds: Cost Modeling, Cost Estimate, Construct

\section{Introduction}

Project cost is one of the most important criteria of success of project and is of high concern to those who are involved in the construction industry.

According to the American Association of Cost Engineers, (AACE) cost engineering is defined as that area of engineering practice where engineering judgment and experience are utilized in the application of scientific principles and techniques to the problem of cost estimation, cost control and profitability. In Albania like other countries construction industry is one of major industry contributing significantly in the growth of socio-economic development. Achieving project completion on time and within budget at specified quality standards is major criterion of success of project (NEDO, 1988). Studies show that rarely projects are completed within stipulated budget.

Although in Albania a lot of money has been spent in construction, the industry is facing a lot of challenges such as the expenditure exceeding the budget, delay to complete the project in time, the building defects

Aim and Objectives of the study was to asses, indentify and classify current forecasting techniques in terms of the techniques used, their accuracy, levels of us age and deficiencies used in several construstion projects in Albania and collecting information about the impact and efficiency of these models and costinfluecing in Albanian construction industry.

\section{Literature Review}

For use of cost modeling techniques in the Design Stage of the Development Process (Fortune and Lees,1996) surveyed cost modeling technique usage during "early cost advice" by "organizations" in Northern England and Wales. Consulting quantity surveying firms made up $62.6 \%$ of the sample frame in this study, the remainder comprising project management, contracting and multidisciplinary organizations local and regional authorities. Later studies were conducted by Fortune and Hinks into 
the use of cost modeling techniques by consultant quantity surveyors in the provision of "early cost advice" throughout the whole of England (Fortune and Hinks, 1998). The results of these studies are shown in Table 1.

The result of these surveyors indicate that traditional cost modeling have the highest relative incidence of model usage and resource and process based cost modeling the lowest incidence in usage (product based cost modeling refer traditional cost modeling, while resource based modeling techniques refer non -traditional cost modeling).

Table 1 -Use of various cost modeling techniques by Northern England (Organizations"(1996)and all England Quantity Surveyors (1998)_-(Source: Fortune and Lees, 1996, Fortune and Hinks,1998).

\begin{tabular}{lll}
\hline Model & $\begin{array}{l}\text { Incidence in use (\% of } \\
\text { Respondents Fortune and } \\
\text { Lees) } 1996\end{array}$ & $\begin{array}{l}\text { Incidence in use (\% of Respondents } \\
\text { Fortune and Lees) } 1998\end{array}$ \\
\hline Judgement & 85.80 & 82.96 \\
Functional unit & 75.50 & 69.74 \\
Cost per m2(superficial) & 97.30 & 96.98 \\
Principal Items & 47.30 & 39.57 \\
Interpolation & 87.00 & 84.13 \\
Elemental Analysis & 88.70 & 88.05 \\
Significant Items & 73.70 & 69.83 \\
Approximate quantities & 96.20 & 93.34 \\
Detailed Quantities & 68.70 & 63.66 \\
Resourse Based & 50.40 & 46.23 \\
Process Based & 31.80 & 26.35 \\
\hline
\end{tabular}

Studies by Bowen and Edwards, investigating cost modeling techniques employed amongst South African quantity surveying practices, revealed that traditional cost modeling techniques such as elemental analysis and approximate quantities are the most popular method employed (Bowen and Edwards,1998). Additionally, the superficial method and bills of quantities are also employed at particular stages of the design process; i.e. the brief and documentation stages respectively this study revealed that a large proportion $(83 \%)$ of respondents "seldom, if ever, utilize (resource based cost models such as) critical path methods or activity bills of quantities in the preparation of price forecasts".

Studies by Azmi Ahmad Bari exploring the types of construction cost modeling indicate that the traditional types of cost modeling were, in general still widely used and the newer (nontraditional), only the value of cost model, resource based model and lifecycle cost model being general use. The traditional types of cost estimation models continue to be in widespread use irrespective of organizational type and size (Bari, 2000).

Studies by Lawther and Edwards indicate that consultant quantity surveyors generally utilize traditional design cost modeling techniques; such techniques reflecting the design information upon which they are based. These techniques do achieve a tolerable level of accuracy. However, they are deficient in terms of lacking an explicit relationship with the construction process they are purporting to model, and by using distorted cost data to support them. Whilst non-traditional cost modeling techniques have been developed, the traditional product based cost models retain greater favor with consultant quantity surveyors. Reasons proffered for lack of use of resource based cost modeling techniques by consultant quantity surveyors include lack of data, lack of understanding of construction processes and time constraints. These restrictions emanate from the traditional method of building procurement which distinctly separates the design and construction processes and thus militates against the easy transfer of data between the actors engaged in them (Lawther \& Edwards, 2011). 


\subsection{Types of cost model techniques}

From studies and literature review exist two distinct of cost modeling techniques:

Product based - where the completed building is modeled which are identified "Traditional cost modeling techniques).

Process based - where the construction production process is modeled which are identified as nontraditional (Skitmore \& Marston, 1999).To ensure that the reproduction of your illustrations is of a reasonable quality, we advise against the use of shading. The contrast should be as pronounced as possible.

If screenshots are necessary, please make sure that you are happy with the print quality before you send the files.

\subsection{Traditional model}

From studies and literature review the traditional modeling represent picture time and costs and they were based cost modeling techniques model the completed building. The traditional or product based cost modeling techniques identified from the literature are summarized:

1. Conference,

2. Financial method,

3. Functional unit,

4. Superficial,

5. Superficial -perimeter,

6. Cube,

7. Storey enclosure,

8. Approximate quantity,

9. Bill of quantities

\subsection{Non -traditional model}

Non-traditional model or process based focus on cross-function activities. These cross-functional activities have increased severely in number and importance due to the growth of complexity and dependencies. The non-traditional cost modeling techniques identified from the literature are summarized:

1. Statistical / Econometric model (Regression analysis and Causal model),

2. Risk / Simulation model (Monte Carlo simulation and Value management),

3. Knowledge based model

4. Resource based model

5. Life cycle model

\subsection{New wave model}

These models are often referred as a way of "reasoning with uncertainty" and provide a well defined mechanism to deal uncertain an incompletely defined data, so they can make precise deductions from imprecise data. They represent local linear input-output relations of a nonlinear system (Takagi \& Sugeno, 1985).

1. Artificial intelligent system (Neural network and Fuzzy logic),

2. Other models (Environmentally and Sustainable development). 


\subsection{Concluding remarks}

The result of these surveyors indicate that traditional cost modeling have the highest relative incidence of model usage non-traditional cost modeling the lowest incidence in usage. The traditional types of cost estimation models continue to be in widespread use irrespective of organizational type and size.

These are considered usefulon the basis of their ease of application, familiarity and speed and a tolerable level of accuracy (Ashworth, 1995).

However, the same models have also being criticized on the basis that:

> They are not (explicitly) founded upon construction production criteria as the generator of cost (Brandon, 1982; Morton, 1995).

$>$ They do not fully represent the relationship between design decisions and the resulting construction processes (Bowen, 1993).

> They fail to consider the uncertainties of the construction process (Bowen, 1987).

$>\quad$ The cost data used to support such models is often taken from previous projects, previous bills of quantities, price books etc and does not represent cost as a function of resource usage, but rather as a function of the completed building product (Raftery, 1984; Morton, 1995).

Thus the criticisms of traditional product based cost modeling techniques are focused upon two main concerns:

> Firstly, the lack of an explicit relationship between the cost modeling techniques and the construction process.

$>$ Secondly, the use of distorted cost data to support such cost modeling techniques.

All non-traditional cost modeling techniques share a common theme of utilizing the contractor's resource based data during the design process. However despite their potential, the literature contains no reported cases of the use of such resource based cost modeling techniques. Therefore their effectiveness remains a matter of academic conjecture and the question arises as to the extent of use of cost modeling techniques in the design stage of the development process.

\section{Research Methodology}

A questionnaire methodology was adopted to appreciate, to determine and indentify the current cost model techniques. Survey and interviews were distributed among contractor, firms, engineers and project management consultants. It focused in design projects, control projects, methods of building procurement, construction site and included almost all types of projects. Data collected through questionnaire survey was analyzed with PASW statistics program, version 18.

A questionnaire methodology was adopted to appreciate, to determine and indentify the current cost model techniques. Survey and interviews were distributed among contractor, firms, engineers and project management consultants. It focused in design projects, control projects, methods of building procurement, construction site and included almost all types of projects. Data collected through questionnaire survey was analyzed with PASW statistics program, version 18.

\subsection{Questionnaire designs}

The questionnaire consisted of two parts - A and B.

2.3.1 Part A-Identification and classification the most widespread or preferred cost estimate models used in construction projects (traditional cost model and non-traditional cost model).

Part $\mathrm{A}$ is divided in 3 sections:

- Section A -general information and demography 
- Section B -indentification and classification the most widespread or prefered cost estimate models used in construstion projects ( traditional cost model and non-traditional cost model)

- Section C- The impact and efficiency of these models in construction industry

\subsection{Conducting questionnaire survey through postal mail and personal interviews}

Questionnaire survey and interviews were distributed among contractor, firms, engineers and project management consultants through postal mail and personal interviews. It focused in design projects, control projects, methods of building procurement, construction site and included almost all types of projects in construction. A total of 150 questionnaires were distributed out of which 28 with a percentage $18.7 \%$ were received.

\subsection{Assessment of feedback from questionnaire survey}

For assessing the degree of accurate and importance of cost model in the part A of questionare a scale is used as follows:

- Not at all

- Some

- Very important

\section{Cost Modeling Process}

This chapter is dedicated to the processes are involved in cost estimating model, choices of estimation models, descriptions of cost model, stages of cost estimates in construction industry and cost estimating from the engineering perspective and the role of the engineers in the cost estimating process.

\subsection{The processes are involved in cost estimating model}

Based on Part 1 of the British Standard BS 6143 (BSI, 1992), a generic process cost model for a construction process is presented in Figure 1. Process approach is one of the eight quality management principles incorporated in the ISO 9000:2000 quality standard. The Standard also emphasizes the importance of continual improvement of processes.

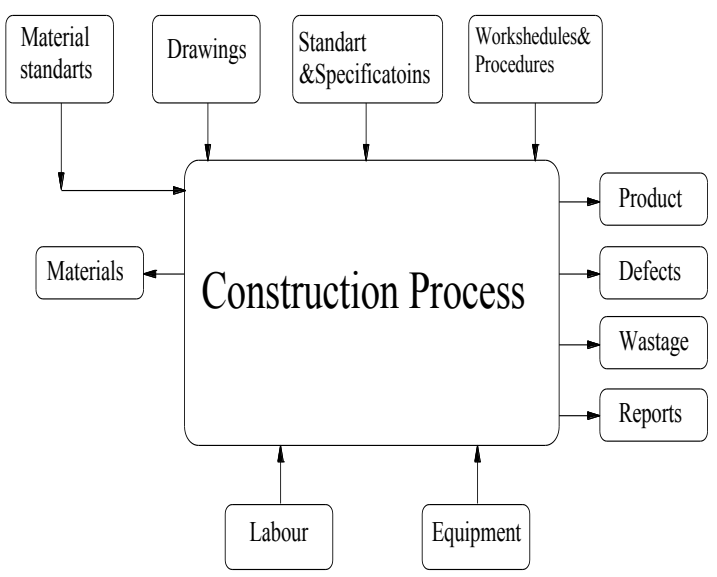

Figure.1. Typical Construction Process Cost Model

Cost estimating is one of the most important steps in project management. A cost estimate establishes the base line of the project cost at different stages of development of the project. A cost estimate at a 
given stage of project development represents a prediction provided by the cost engineer or estimator on the basis of available data. More specifically, the management decisions supported by cost models include:

- Forecasting the total cost of construction

- Comparing design alternatives

- Forecasting the economic effects upon society of changes to design codes and regulations

\subsection{Factors influencing the choice of cost model}

Many factors influence of cost model. Some of them are mention below:

- Information and time available;

- Experience of the estimator/quantity surveyor;

- The amount and the form of cost data;

- Purpose of the estimates;

- Techniques to be adopted ;

Cost estimate can be done in any stage of the project. A construction project is considered in 6 different stages:

- Feasibility stage

- Conceptual stage

- Design stage

- Procurement

- Construction

- Turnover

Conceptual cost estimation is performed in conceptualstage detailed design is completed. In conceptual stage, the preliminary design of the project has been finished. Preliminary drawings and specifications are the only sources that can be used in conceptualcost estimation. At the early stages of a construction project the design information and scope definitions are very limited, hence achieving high accuracy is very difficult.

The accuracy of cost estimating increases due to the finalized drawing and specifications and specifications from feasibility to turnover stage. All parties involved in a project need to know about the cost of the project from the first stage (from feasibility stage) to last stage (turnover stage). Virtually all cost estimation is performed according to one or some combination of the following basic approaches.

Conceptual cost estimating methods are:

- Unit cost model

- Factor cost model

- Probabilistic Modeling \& Simulation

\subsection{Cost model method descriptions}

- Conference,

- Financial method,

- Functional unit,

- Superficial, 
- Superficial -perimeter,

- Cube,

- Storey enclosure,

- Approximate quantity,

- Bill of quantities

- Statistical / Econometric model (Regression analysis and Causal model),

- Risk / Simulation model (Monte Carlo simulation and Value management),

- Knowledge based model

- Resource based model

- Life cycle model

\subsubsection{Conference method}

a) Estimates cost functions on the basis of analysis and opinions about costs and the ir drivers gathered from various departments of a company;

b) Pools expert knowledge;

Reliance on opinions still makes this method subjective.

\subsubsection{Financial methods}

This method is used to determine cost limits or the building costs in a developer's budget.

\subsubsection{Functional unit}

A monetary rate or amount applied to a unit commensurate with the function of the building. Applicable to projects having standard units of accommodation. Often used to fix cost limits for public sector building projects.

\subsubsection{Superficial}

A single rate applied to the floor area of a building e.g. $\$ / \mathrm{m} 2$.Still widely used, and the most popular method of approximate estimating can be applied to virtually all types of buildings.

\subsubsection{Superficial perimeter(Ashworth ,1995)}

As well as taking the floor area of a building into account, the length of building perimeter is also included in an endeavor to increase accuracy. Never used in practice.

\subsubsection{Cube(Smith,1998)}

A single cost rate applied to the internal volume of building. Used mainly by architects, but now in disuse.

\subsubsection{Storey enclosure}

Measurement and evaluation of any area within a building. Unusable in practice.

\subsubsection{Approximate quantities}

Measurement and the price of small items grouped. This method is still a popular meth od on difficult and award contracts and where time permits.

\subsubsection{Resource analysis}

Used mainly by contractors for contract estimating and tendering and tendering purposes.

\subsubsection{Regression analysis}


Regression analysis is a statisticalmethod that measures the average amount of change in the dependent variable associated with a unit change in one or more independent variables.

\section{Types of regression}

a) Simple - estimates the relationship between the dependent variable and one independent variable;

b) Multiple - estimates the relationship between the dependent variable and two or more independent variable;

Therefore, all methods, techniques or procedures used by quantity surveyors for cost estimation or cost forecast may be termed as cost models quantity.

\section{Results And Analysis}

This chapter is dedicated to the results and analys is of data collected. It consists in analys is of respondent profile, advantages and disadvantages of the cost modeling techniques.

\subsection{Respondent Profile}

The results indicates the majority (almost 100\%) possess a high level of academic qualification; i.e. degree holders. Majority covers a spectrum of high ranking personnel in which (81\%) of the respondents belong to the top management level, such as director, principal, managing here director, etc. Therefore, the information provided by the respondents can be considered as reliable and authoritative. Majority of terms involved in questionnaire are described as below:

\subsubsection{The job position.}

Distribution of respondents in terms of job position is shown in tab.2. The majority of respondents are classified as below:

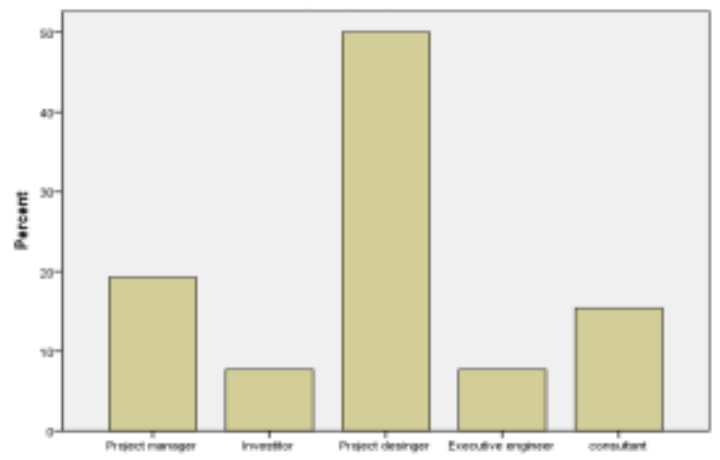

Fig..3. Bar chart of job position

\subsubsection{Practical experience working in constructions projects.}

Distribution of respondents in terms experience working is shown in table 3 indicates that majority of respondent's i.e. $51.9 \%$ were experienced less than 5 years and $22.2 \%$ had experience between 11 15 years. 


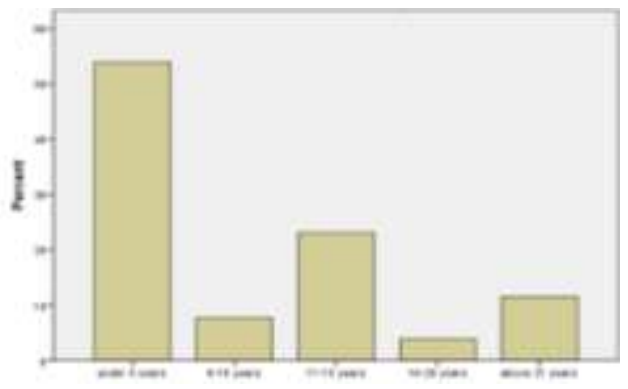

Fig.4.Bar chart frequency of experience working in constructions projects

\subsubsection{Types of projects}

Distribution of respondents in term "type's projects" is shown in table 4 indicates that majority of respondent's i.e. $46.2 \%$ were experienced in industrial construction.

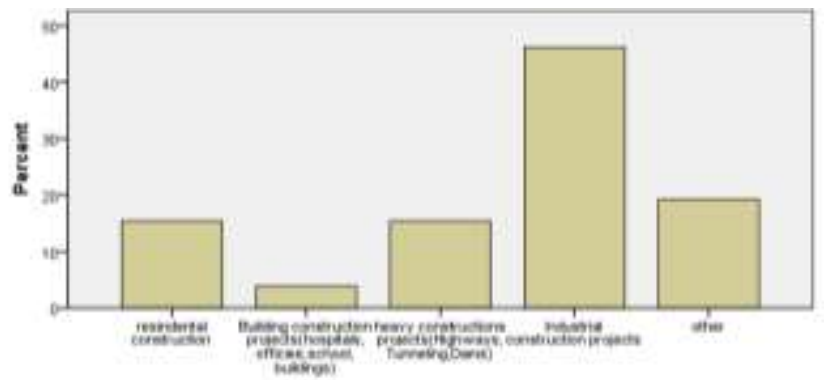

Fig.5.Bar chart the types of projects

\section{Data collected}

Identification and classification cost estimate models used in construction projects

The results of these surveys indicate that traditional cost modeling techniques such as bill quantities the most popular methods employed. Additionally approximate quantities, the superficial method and financial method are also employed at particular stages of the design process;

Frequency of models the company currently-used is shown in table 5. The results indicate that $100 \%$ of respondent's used traditional cost model.

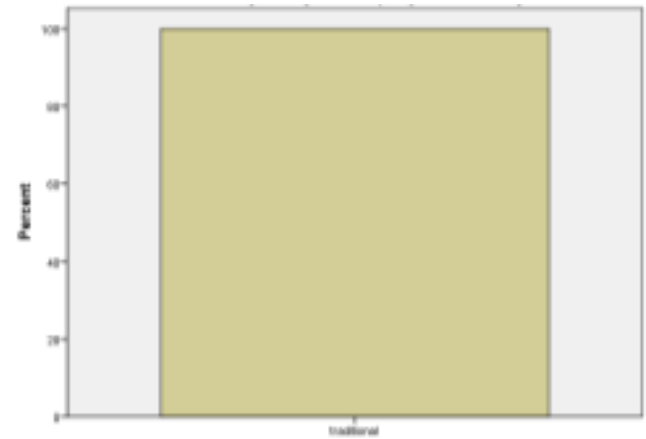

Fig..6..Bar chart of models currently -used 


\section{Frequency of types for traditional models}

Distribution of respondents in term of "Which type of traditional models you often use?" is shown in table 6. The results indicate that $92.6 \%$ of respondent's use "Bill quantities and $3.7 \%$ "Financial Method" traditional cost model.

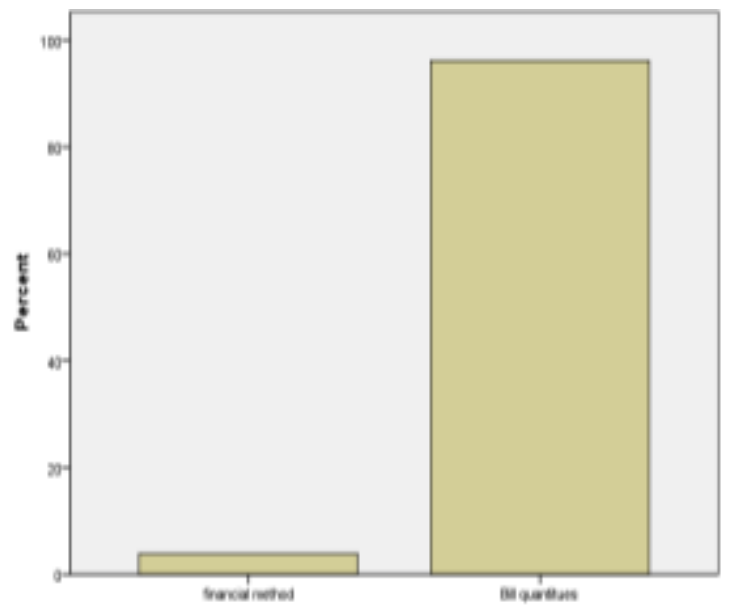

Fig.7. Bar chart of types for traditional models

\section{Accuracy Cost Modeling Techniques}

Distribution of respondents in term of " Accurate "cost modeling is fundamental to the efficiency of construction?" is shown in table 7. The results indicate that $85.2 \%$ the "Accurate "cost modeling is very important in fundamental to the efficiency of construction.

- Highlight the items with most effect on the project cost;

- It determines clearly and accurately the cost of a project and minimizes it;

- Make possible the use of method cost can be done even the verification comparison with the bidders and subcontractors for their enterprising according to the activities $\mathrm{cm} / \mathrm{unit}$;

- Indentification the real cost of project;

\section{Dis advantages of traditional cost modeling techniques}

The resultants indicate the same models have also being criticized on the basis that:

- Cost as usual is recalculated because there are always delays in procurement and the time of drafting the project until the beginning of its implementation;

- The prices refer book price are different to the market and are delayed updated in terms of a variety of materials and new inputs coming from outside;

- They do not fully represent the relationship between design decisions and the resulting construction processes;

\section{Newer cost modeling techniques}

Distribution of respondents in term of "Which one of nontraditional models you know" is shown in figure 10. The results indicate that $88.9 \%$ didn't know these models. 


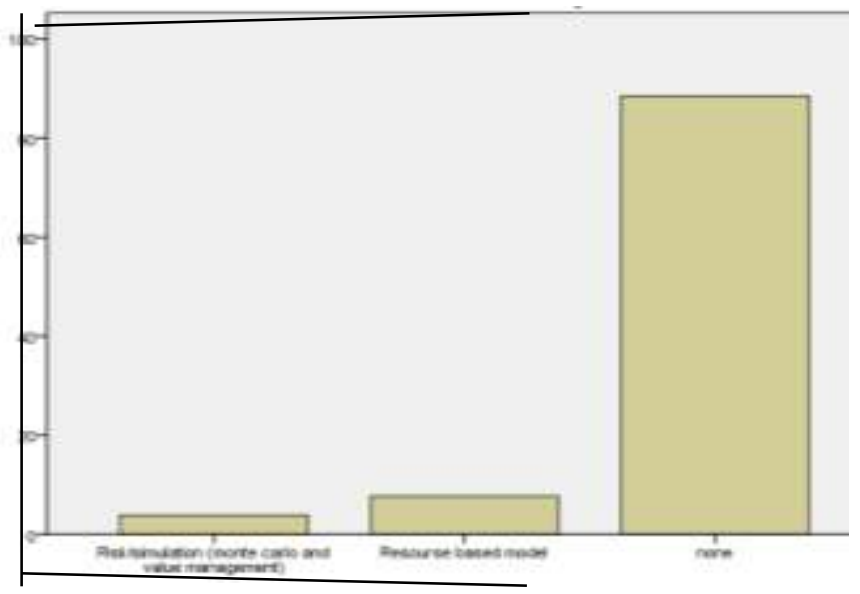

Fig.10.Bar chart of non-traditional cost model

\section{Reliability of newer techniques of cost estimate model}

Distribution of respondents in term of "Which one of nontraditional models you know" is shown in table 9. The results indicate that $88.9 \%$ indicate that" newer techniques model" are reliable

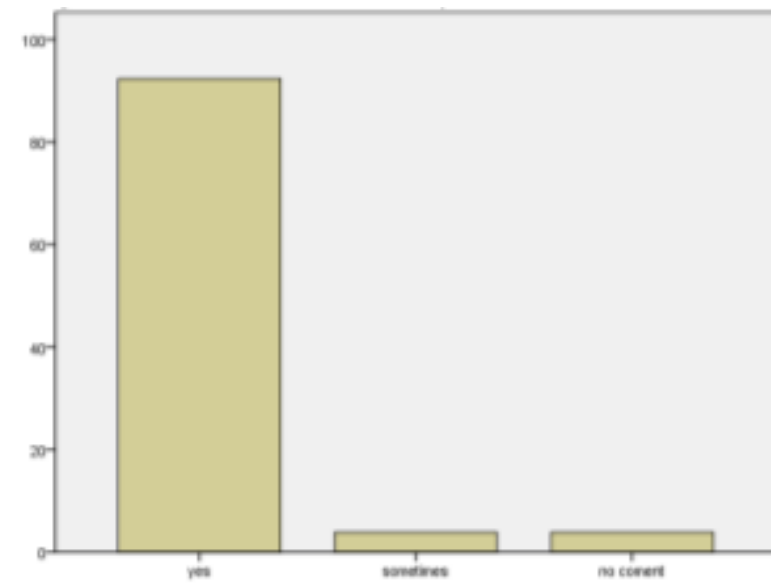

Fig.11.Bar chart for reliable the newer techniques of cost estimate model

\section{Deficiencies of newer techniques of cost estimate model}

The respondents classified some deficiencies, which are presented as below:

- Lack of familiarity with the newer techniques;

- Lack of knowledge to evaluate the risk ;

- Financial constrains;

- Lack of knowledge management techniques;

- Doubts whether these techniques are applicable to other projects;

- Most construction projects are not large enough to warrant the use of these techniques or research into them;

- New's techniques needs training on software investment;

- Not everyone in the bussines can understand;

- Requires more proffesional expertise on learning and operating model costs of the projects;

- Difficult to adopt with the national experience and standards; 
- Require trained people on working and operating with them;

- Require highly qualified and well-known, be simple and easily integrated in the company who want to make part of their own

\section{Conclusions}

The result of this paper indicate that traditional cost modeling have the highest relative incidence of model usage and non-traditional cost modeling the lowest incidence in usage. The traditional types of cost estimation models continue to be in widespread use irrespective of organizational type and size.The traditional cost model are considered useful on the basis that:

- Understandable, the experience of these models and doesn't need training;

- Applied by the legal structure having no risk for the application;

- The construction carry out with optimal wastage (expense) achiving the objectives of contractor;

- More adaptable;

- Estimates the cost of the projects in a short time and following the well-known international standarts;

- Highlight the items with most effect on the project cost;

- It determines clearly and accurately the cost of a project and minimizes it;

- Make possible the use of method cost can be done even the verification comparison with the bidders and subcontractors for their enterprising according to the activities $\mathrm{cm} / \mathrm{unit}$;

- Indentification the real cost of project;

Desipte their avantages, are being criticized on the bas is of their recalculating because there are always delays in procurement and the time of drafting the project until the beginning of its implementation, prices refer book price are different to the market and are delayed updated in terms of a variety of materials and new inputs coming from outside, do not fully represent the relationship between design decisions and the resulting construction processes.

The newer cost model techniques, remain only in information phase and not seen the trend in their usege. The disavantages of the newer cost model are considered:

- $\quad$ Lack of familiarity with the newer techniques;

- Lack of knowledge to evaluate the risk ;

- Financial constrains;

- Lack of knowledge management techniques;

- Doubts whether these techniques are replicable to other projects;

- Most construction projects are not large enough to warrant the use of these techniques or research into them;

- New's techniques needs training on software investment;

- Not everyone in the bussines can understand;

- Requires more proffesional expertise on learning and operating model costs of the projects;

- Difficult to adopt with the national experience and standards;

- $\quad$ Require trained people on working and operating with them;

- Require highly qualified and well-known be simple and easily integrated in the company who want to make part of their own.

\section{References}

1. Ashworth, A. (1995) Cost Studies of Buildings. 2nd Edition. Longman Group, London.

2. Ashworth, A. and Skitmore, R.M. (1983) Accuracy in estimating. Occasional Paper No. 27. Chartered Institute of Building. United Kingdom. 
3. Bowen, P.A. and Edwards, P.J. (1998) Building Cost Planning and Cost Information Management in South Africa, Journal of Construction Procurement, Vol.4, No.1, pp16-26. The International Procurement Research Group. Glamorgan University, United Kingdom.

4. Bowen, P.A. (1993) A communication based approach to price modeling and price forecasting in the design phase of the traditional building procurement process in South Africa. Unpublished PhD thesis, University of Port Elizabeth, South Africa.

5. Bowen, P.A, Wolvaardt, and J.S, Taylor, R.G. (1987) Cost modeling: a process modeling approach. In

6. Building Cost Modeling and Computers, Brandon, P.(ed). E\&FN Spon, London.

7. Design cost modeling - A way forward (Peter M Lawther and Peter J Edwards Department of Building and Construction Economics Royal Melbourne University of Technology University, Australia).

8. Exploring the types of construction cost modeling for industrialized building system(IBS)project in Malaysia ---Nor Azmi Ahmad Bari )University Putra Malaysia.

9. Fortune, C. and Lees, M. (1996) the relative performance of new and traditional cost models in strategic advice for clients. RICS Research Paper Series, Vol.2, No.2, March. Royal Institution Chartered Surveyors, London.

10. Fortune, C. and Hinks, J. (1998) Strategic building project price forecasting models in use paradigm shift postponed. Journal of Financial Management of Property and Construction.

11. Appendix 1

12. The Questionnaire -Part I

13. The Questionnaire -Consisted Of Two Parts - I And Ii.

14. Part I Is Divided In 3 Sections

15. The Section A Consisted Of:

16. General Information And Demography (E.G. Work Experience, Position In Company)

17. The Section B Consisted Of:

18. Indentification And Classification The Most Widespread Or Prefered Cost Estimate Models Used In Construstion Projects (Traditional Cost Model And Non-Traditional Cost Model)

19. Section A - General Information And Demography 